\title{
Treatment of Waterborne Coating Wastewater by Coagulation Sedimentation Fenton Oxidation Process
}

\author{
Chenxi Yang 1,2,3,4, , Jian Wang 1,2,3,4 \\ ${ }^{1}$ Institute of Land Engineering and Technology, Shaanxi Provincial Land Engineering Construction Group Co., Ltd., Xi'an 710075 , \\ China \\ ${ }^{2}$ ShaanXi Provincial Land Engineering Construction Group Co., Ltd., Xi'an 710075, China \\ ${ }^{3}$ Key Laboratory of Degraded and Unused Land Consolidation Engineering, the Ministry of Land and Resources, Xi'an 710075, China \\ ${ }^{4}$ Shaanxi Provincial Land Consolidation Engineering Technology Research Center, Xi'an 710075, China
}

\begin{abstract}
: waterborne coatings have become the development trend of the coating industry because of their less use of organic solvents and good environmental protection performance. However, the wastewater produced in the production process of waterborne coatings has become a difficult pollution source. Based on this, this paper uses coagulation sedimentation method and Fenton oxidation method to treat waterborne coating wastewater. Taking the COD of treated wastewater as the research index, this paper studies various factors affecting the treatment effect of coagulation sedimentation and Fenton oxidation. Through single factor analysis, the results show that the best dosage of PFS and PAM is PFS: $8 \mathrm{~g} / \mathrm{L}$ and PAM: $0.8 \mathrm{~g} / \mathrm{L}$; In Fenton oxidation, the dosage of $\mathrm{H} 2 \mathrm{O} 2$ is $9.98 \mathrm{~mL} / \mathrm{L}$, the dosage of $\mathrm{FeSO} 4 \cdot 7 \mathrm{H} 2 \mathrm{O}$ is $\mathrm{n}(\mathrm{Fe} 2+): \mathrm{n}(\mathrm{H} 2 \mathrm{O} 2)=$ $1: 6, \mathrm{pH}$ is 2 , and the dosage times are 2 .
\end{abstract}

Key words: coagulation sedimentation, Fenton oxidation, waterborne coating wastewater

\section{Introduction}

The water-based coating takes water as the dispersion medium. During the construction and subsequent drying process, the water volatilizes and returns to nature in a gas state, which will not harm the human body and the environment. Therefore, with the enhancement of people's awareness of environmental protection and the government's efforts to improve environmental protection, the water-based coating has become more and more popular [1,2]. However, in the production process, waterbased coatings will produce a large amount of wastewater with high chroma, turbidity and COD content $[3,4]$. Therefore, how to treat water-based coating wastewater in an economical and simple way to make it meet the national discharge standard has become a major problem in water pollution control.

The main components of waterborne coatings include waterborne acrylic resin (film-forming material), deionized water, film-forming additives, wetting agent, defoamer, leveling agent, $\mathrm{pH}$ regulator, preservative, thickener, filler, pigment, etc [5]. The main sources of wastewater are batching tank washing liquid and cleaning wastewater. In principle, the washing solution of batching tank is the wastewater after the dilution of the original coating sample solution, so its chroma, turbidity and COD content are large. At present, aiming at the basically known pollution sources and types of water-based coating wastewater, the methods for treating this kind of organic wastewater at home and abroad mainly include incineration method, coagulation sedimentation method, chemical oxidation method, electrolysis method, biological method and combined method [6].

Taking the waterborne coating wastewater produced by a waterborne coating production company in Guangdong as the research object, this paper discusses the treatment conditions of waterborne coating wastewater by coagulation sedimentation method and Fenton oxidation method. Taking the COD removal rate as the screening index, various factors were compared and analyzed and the optimization conditions were studied.

\section{Experiment}

\subsection{Materials and instruments}

The reflux condenser, $250 \mathrm{~mL}$ conical flask, heating jacket, acid burette and thermometer are all purchased from the local chemical glass station. Silver sulfate (Ag2SO4, AR), mercury sulfate (HgSO4, AR), sulfuric acid (H2SO4, AR), phenanthroline (AR), potassium hydrogen phthalate (AR), polymeric ferric sulfate (PFS, AR), polypropylamide (PAM, AR), H2O2 (30\%), ferric sulfate heptahydrate (FeSO4.7H2O, AR) and sodium hydroxide $(\mathrm{NaOH}, \mathrm{AR})$ were purchased from Sinopharm group.

\footnotetext{
* Corresponding author: 1098002212@qq.com
} 


\subsection{Coagulation sedimentation method}

PFS is selected as coagulant and PAM as coagulant aid. Take several $100 \mathrm{mLwater}$ samples into the beaker, add 8 $\mathrm{g} / \mathrm{L}$ PFS and $0.6 \mathrm{~g} / \mathrm{L}$ PAM respectively for coagulation test, and conduct the experiment by selecting the stirring strategy of fast stirring for $1 \mathrm{~min}$ and slow stirring for 1.5 min, and then set the sedimentation time as $1 \mathrm{~h}$.

\subsection{Fenton oxidation method}

$\mathrm{H}_{2} \mathrm{O}_{2}$ dosage, $\mathrm{FeSO}_{4} \cdot 7 \mathrm{H}_{2} \mathrm{O}$ dosage, $\mathrm{pH}$ value and dosing times are selected as the control conditions. According to the literature, the ratio of $\mathrm{n}\left(\mathrm{Fe}^{2+}\right): \mathrm{n}\left(\mathrm{H}_{2} \mathrm{O}_{2}\right)$ is 1:5 8. Therefore, the amount of $\mathrm{FeSO}_{4} \cdot 7 \mathrm{H}_{2} \mathrm{O}$ is calculated by calculating the amount of $\mathrm{H}_{2} \mathrm{O}_{2}$. The single factor test is carried out by controlling the variable method, so as to determine the optimal conditions of $\mathrm{H}_{2} \mathrm{O}_{2}$ dosage, $\mathrm{FeSO}_{4} \cdot 7 \mathrm{H}_{2} \mathrm{O}$ dosage, $\mathrm{pH}$ value and dosing times.

\section{Result Analysis}

\subsection{Treatment effect of coagulation sedimentation}

Coagulation sedimentation can make the colloids and suspended solids in wastewater agglomerate into flocs through coagulation through the addition of coagulant, so as to precipitate and separate pollutants through sedimentation. The dosage of coagulant PFS and coagulant aid PAM determines the treatment efficiency of coagulation sedimentation. In the test, different amounts of PFS and PAM are added to treat coating wastewater, and the COD content of effluent is shown in Figure 1. With the increase of PFS dosage, the effluent COD decreases sharply. When the dosage increases to $8 \mathrm{~g} / \mathrm{L}$, the effluent COD removal rate reaches the peak. If the dosage of PFS continues to increase, the effluent COD decreases. The addition of PFS will hydrolyze and polymerize to form a variety of colloidal complex ions, which will promote the suspended solids and other pollutants in the coating to gather into flocs, so that the pollution can precipitate in the form of coagulation and sedimentation. However, when PFS is excessive, the opposite charges in the colloid will attract each other to form a new stable system, which reduces the coagulation and precipitation effect. Therefore, the optimal mass concentration of PFS is $8 \mathrm{~g} / \mathrm{L}$.

When the amount of PFS is controlled to be $8 \mathrm{~g} / \mathrm{L}$, the effect of different coagulant aid dosage on COD removal rate is shown in Fig. 2 (b). The COD content of effluent decreased with the increase of PAM dosage, and reached the highest value at $0.8 \mathrm{~g} / \mathrm{L}$. When the dosage of PAM continues to increase, the COD of effluent will increase. This is because too many polymers will cover the surface of colloidal particles, and the polymers will repel each other due to the same charge, so that the colloidal particles cannot gather. Moreover, because PAM is a high molecular organic matter, when the dosage of PAM is excessive, only one part will precipitate through bridging adsorption, and the other part will remain in the supernatant to increase the cod, The removal rate becomes smaller. Therefore, the best mass concentration of PAM is $0.8 \mathrm{~g} / \mathrm{L}$.


Figure 1. (a) effect of PFS dosage on effluent COD; (b) Effect of PAM dosage on effluent COD.

\subsection{Treatment of coating wastewater by Fenton oxidation}

\subsubsection{Influence of H2O2 Dosage on Treatment Effect}

Fenton process refers to the reaction between $\mathrm{H}_{2} \mathrm{O}_{2}$ and $\mathrm{Fe}^{2+}$ to produce $\cdot \mathrm{oh}$. This hydroxyl radical can oxidize the organic matter in coating wastewater, so as to shorten the molecular chain segment of organic matter or mineralize it into $\mathrm{CO}_{2}$ and $\mathrm{H}_{2} \mathrm{O}$. The $\cdot \mathrm{OH}$ produced by $\mathrm{H}_{2} \mathrm{O}_{2}$ is the core of chemical oxidation method. Therefore, firstly, the effect of $\mathrm{H}_{2} \mathrm{O}_{2}$ dosage on Fenton reaction is studied. Experimental conditions: the wastewater used in Fenton oxidation treatment is the wastewater treated under the best conditions of coagulation and sedimentation. At this time, the COD is $1380 \mathrm{mg} / \mathrm{L}$. the effect of $\mathrm{H}_{2} \mathrm{O}_{2}$ on Fenton reaction is determined by fixing the dosage of $\mathrm{FeSO}_{4} \cdot 7 \mathrm{H}_{2} \mathrm{O}$ as n $(\mathrm{Fe} 2+): \mathrm{n}\left(\mathrm{H}_{2} \mathrm{O}_{2}\right)=1: 6$ And $\mathrm{pH} 2$. The amount of $\mathrm{H}_{2} \mathrm{O}_{2}$ added is $1.66 \mathrm{~mL} / \mathrm{L}, 3.33 \mathrm{~mL} / \mathrm{L}, 6.65$ $\mathrm{mL} / \mathrm{L}, \quad 9.98 \mathrm{~mL} / \mathrm{L}, \quad 13.30 \mathrm{~mL} / \mathrm{L}$ and $16.63 \mathrm{~mL} / \mathrm{L}$ respectively. After adjusting the $\mathrm{pH}$ to 2 , detect the CODcr concentration and turbidity. The results are shown in Figure 2. 


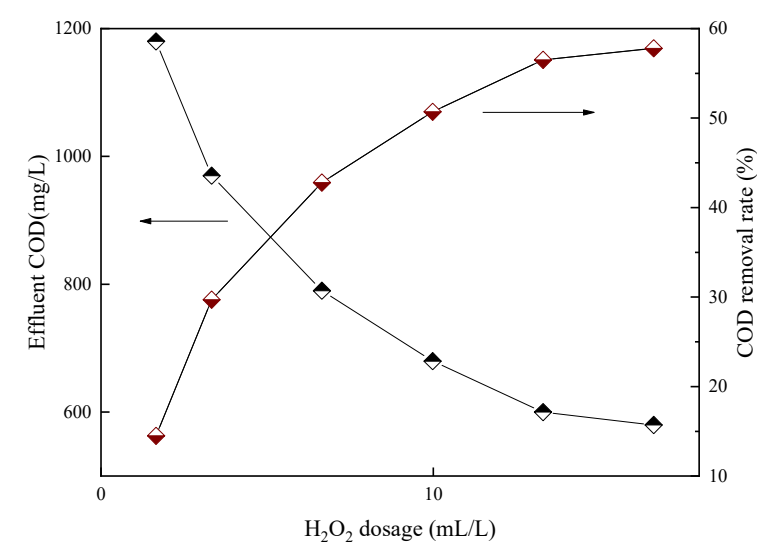

Figure 2. Effect of $\mathrm{H}_{2} \mathrm{O}_{2}$ dosage on COD removal effect

It can be seen from Figure 2 that the dosage of $\mathrm{H}_{2} \mathrm{O}_{2}$ will affect the treatment effect of wastewater. When the dosage was less than $9.98 \mathrm{~mL} / \mathrm{L}$, the CODcr removal rate increased significantly with the increase of $\mathrm{H}_{2} \mathrm{O}_{2}$ dosage; After $9.98 \mathrm{~mL} / \mathrm{L}$, the change of CODcr removal rate tends to be gentle. This is because when the $\mathrm{H}_{2} \mathrm{O}_{2}$ dosage is low, with the increase of $\mathrm{H}_{2} \mathrm{O}_{2}$ dosage, $\mathrm{H}_{2} \mathrm{O}_{2}$ will produce more $\cdot \mathrm{OH}$, so as to oxidize organic matter, reduce COD and increase COD removal rate. When the dosage of $\mathrm{H}_{2} \mathrm{O}_{2}$ is greater than $9.98 \mathrm{ml} / 1$, even adding more $\mathrm{H}_{2} \mathrm{O}_{2}$ will not reduce the COD of wastewater, because adding more $\mathrm{H}_{2} \mathrm{O}_{2}$ will only produce ineffective decomposition and cannot increase the COD removal rate. Therefore, it can be seen from the above data that the optimal $\mathrm{H}_{2} \mathrm{O}_{2}$ dosage for wastewater treatment is $9.98 \mathrm{~mL} / \mathrm{L}$.

\subsubsection{Effect of $\mathrm{pH}$ on Treatment Effect}

According to the wastewater treatment mechanism of Fenton oxidation reaction, $\mathrm{pH}$ value will affect the direction of reaction. From the reaction formula $\mathrm{Fe}^{2+}+$ $\mathrm{H}_{2} \mathrm{O}_{2} \rightarrow \mathrm{Fe}^{3+}+\mathrm{OH}+\cdot \mathrm{OH}$, it can be seen that $\mathrm{Oh}$ will be continuously consumed under acidic conditions, which promotes the reaction to the right. When the $\mathrm{pH}$ is low, it will inhibit the progress of the above reaction and reduce the production of $\cdot \mathrm{OH}$. In order to explore the optimal $\mathrm{pH}$ value of oxidation treatment of waterborne coating wastewater, the optimal $\mathrm{pH}$ value of Fenton reaction in waterborne coating wastewater was studied by controlling single factor experiment. Experimental conditions: the experimental raw water is the wastewater treated under the best conditions of coagulation and sedimentation. The COD is $1380 \mathrm{mg} / \mathrm{L}$, the dosage of $\mathrm{H}_{2} \mathrm{O}_{2}$ is $9.98 \mathrm{~mL} / \mathrm{L}$, and the dosage of $\mathrm{FeSO}_{4} \cdot 7 \mathrm{H}_{2} \mathrm{O}$ is $3.03 \mathrm{~g} / \mathrm{L}$ calculated according to $n\left(\mathrm{Fe}^{2+}\right): n\left(\mathrm{H}_{2} \mathrm{O}_{2}\right)=1: 6$. The effect of $\mathrm{pH}$ on Fenton reaction was studied by changing $\mathrm{pH}$, and the results are shown in Fig. 3.

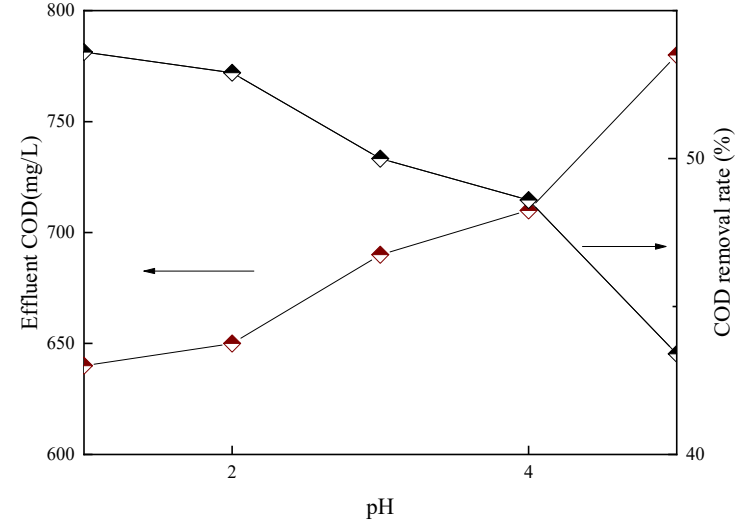

Figure 3. Effect of pH Dosage on COD Removal Effect

As shown in Figure 3, pH will affect the effect of Fenton oxidation treatment of wastewater. The COD of waterbased coating wastewater after Fenton oxidation treatment decreases with the decrease of $\mathrm{pH}$, and the COD removal rate increases. When the $\mathrm{pH}$ is 2 , the effluent COD reaches the peak value of this single factor test treatment. When the $\mathrm{pH}$ continues to decrease to 1 , the COD of the treated wastewater basically does not change. It shows that the Fenton reaction has reached the best acidic condition of Fenton oxidation reaction when the $\mathrm{pH}$ is 2 . Further reducing the $\mathrm{pH}$ can not continue to improve the oxidation treatment effect. Therefore, when the $\mathrm{pH}$ is 2 , it can be used as the best $\mathrm{pH}$ for Fenton oxidation treatment of waterborne coating wastewater. [7]

\section{Conclusion}

The optimal treatment conditions were explored by coagulation sedimentation and Fenton oxidation. The following conclusions are drawn through the single factor test method:

(1) The effect of PFS and PAM dosage on effluent COD in coagulation sedimentation method is discussed through single factor experiment. The optimal conditions are PFS: $8 \mathrm{~g} / \mathrm{L}$ and PAM: $0.8 \mathrm{~g} / \mathrm{L}$.

(2) According to the experimental results of Fenton oxidation reaction, the optimal reaction conditions for COD removal rate are determined: the dosage of $\mathrm{H}_{2} \mathrm{O} 2$ is $9.98 \mathrm{~mL} / \mathrm{L}$; The dosage of $\mathrm{FeSO}_{4} \cdot 7 \mathrm{H}_{2} \mathrm{O}$ is: $\mathrm{n}\left(\mathrm{Fe}^{2+}\right): \mathrm{n}$ $\left(\mathrm{H}_{2} \mathrm{O}_{2}\right)=1: 6$; PH 2; The number of dosing is 2 .

\section{Acknowledgments}

This work was financially supported by Shaanxi Provincial Land Engineering Construction Group internal research project (DJNY2021-22) fund.

\section{Reference}

1. Chen Xiuning, Xu Ning, he Chenglin, Yang Jinsong, $\mathrm{Xu}$ Yuhua, Xu Yujun, Lin Jianxin. Current situation and Prospect of waterborne coatings [J]. Coating technology and abstracts, 2016,37 (03): 41-45 
2. Wang Xiaoming. Research on waterborne acrylic resin coatings [D]. Nanjing University of Aeronautics and Astronautics, 2012

3. Tang Hongxia. Analysis on hazardous characteristics of sludge from water-based building coating wastewater treatment $[\mathrm{J}]$. Environmental protection science, 2019,45 (04): 45-49

4. Zhang Zhonghua. Emulsion wastewater treatment during waterborne coatings production $[\mathrm{J}]$. China building waterproofing, 2018 (21): 34-36.

5. Tang Benhui. Study on compatibility of waterborne wood coating additives [D]. South China University of technology, 2013

6. Xing Yao, Cheng Aihua. Study on the treatment of camouflage coating wastewater by coagulation Fenton oxidation $[\mathrm{J}]$. Industrial water treatment, 2016, 36 (07): 48-51

7. Song Xiaozhi. Wastewater treatment technology for coating additive production [J]. Water purification technology, 2014, 33 (S1): 64-67 